\title{
A RESOLUÇÃO SENATORIAL NO CONTROLE DIFUSO DE CONSTITUCIONALIDADE
}

THE SENATORIAL RESOLUTION IN THE DIFFUSE CONSTITUTIONAL REVIEW

\section{Thomas Ribeiro Bergmann*}

Submissão: 03/06/2013

Aceito para Publicação: 14/08/2013

Sumário: Introdução. 1. A Controvérsia e as Premissas de uma Solução. 1.1. Considerações Iniciais. 1.2. Ilegitimidade e Usurpação de Competência. 1.3. Obrigatoriedade ou Discricionariedade? 1.4. Liberdade Quanto à Extensão da Suspensão? 2. A Eficácia Prospectiva da Resolução Senatorial 3. Considerações Finais. Referências.

Resumo: O ordenamento jurídico brasileiro adota um sistema misto de controle de constitucionalidade, isto é, incorpora tanto o controle concentrado, como o controle difuso de constitucionalidade. A Constituição Federal de 1988, na distribuição de competências entre os órgãos do Poder, de molde a ensejar controles recíprocos entre estes, atribui, em seu artigo 52, $\mathrm{X}$, ao Senado Federal a atribuição de “suspender” dispositivos legais declarados contrários à Lei Maior pelo Supremo Tribunal Federal no exercício do controle de constitucionalidade difuso. Entre acordos e desacordos concernentes ao conteúdo semântico do preceito ora versado, e a despeito da posição da Corte Suprema brasileira, muita controvérsia ainda grassa na dogmática constitucional em torno da eficácia de tal dispositivo. Mostrar-se-á que a melhor solução à questão é dada quando da visualização sistemática da ordenação dos Poderes, ficando clara a relativa liberdade do Senado Federal para a suspensão com efeitos "ex nunc” do preceito legal violador da Carta Republicana.

\footnotetext{
* Fundação Escola Superior do Ministério Público do Rio Grande do Sul.
} 
Palavras-chave: Controle difuso; Senado Federal; Discricionariedade política; inconstitucionalidade; Supremo Tribunal Federal.

Abstract: The Brazilian legal system adopts a mixed form of constitutional review, i.e., it incorporates both the concentrated, and the diffuse review. The 1988 Federal Constitution, in its competence distribution among the power organs, in order to allow reciprocal checks among them, ascribe, in the article 52, X, to the Federal Senate the attribution to "suspend" legal precepts declared contrary to the Constitution by the Supremo Tribunal Federal in its exercise of the diffuse constitutional review. Among agreements and disagreements concerning the semantic content of the precept now analyzed, and despite the position of the Brazilian Supreme Court, a lot of controversy still remains in the constitutional dogmatics about the legal effects of that prescription. It will be shown that the best solution to this issue is given when the systematic ordering of powers is visualized, this way becoming clear the relativity of the Senate's liberty to suspend with "ex nunc" effects the legal precept that violates the Federal Constitution.

Keywords: Diffuse control; Federal Senate; Political Discretionality; Unconstitutionality; Supremo Tribunal Federal.

\section{INTRODUÇÃO}

Desde a entrada em vigor da Carta Republicana de 1988, poucos de seus dispositivos suscitaram tantas discussões na literatura constitucionalista pátria quanto o inscrito no décimo inciso do art. 52 daquela Lei Magna. Trata-se de texto normativo veiculador de uma normaregra de relevância elevadíssima no âmbito do controle de constitucionalidade pela via da exceção e, portanto, no sistema de defesa e restauração de ordem constitucional estatuído pela Constituição Federal de 1988. Tais razões, sucintamente expostas, nos levam a crer ser de máxima importância a discussão e a clarificação de questões emergentes com a positivação da norma em comento. Isto é, na esteira das lições de Ferraz Junior, com a positivação de pontos de partida ao raciocínio dos juristas, os dogmas, com o intuito de clarificação de incertezas, novas incertezas surgem em face da necessidade de interpretação daqueles pontos de partida 
vinculantes, de tal sorte que a primitiva incerteza resta ampliada de uma forma controlada, ou seja, de modo compatível com a vinculação a normas e à pressão para decidir conflitos sociais ${ }^{1}$, daí emergindo novas questões a demandar novas soluções por parte dos juristas.

Muito se discute na doutrina constitucional pátria a respeito da interpretação mais adequada a ser dada ao inciso $\mathrm{X}$ do artigo 52 da Lei Magna, o qual trata das diversas competências atribuídas em caráter de exclusividade ao Senado Federal, Casa representativa dos Estados-membros da federação brasileira e asseguradora da paridade entre os mencionados entes políticos.

Dentro da estrutura normativa da Constituição Federal de 1988, tal preceito se enquadra entre as normas de estabilização constitucional, porquanto consagra elemento importantíssimo para a solução de conflitos constitucionais e para a defesa da Lei Maior. ${ }^{2}$

\section{A CONTROVÉRSIA E AS PREMISSAS DE UMA SOLUÇÃO}

\subsection{Considerações Iniciais}

O referido preceptivo estatui competir privativamente ao Senado Federal "suspender a execução, no todo ou em parte, de lei declarada inconstitucional por decisão definitiva do Supremo Tribunal Federal”.

Trata-se, a rigor, de retirada da eficácia de lei - em sentido formal ou material, aí incluídos, e.g., os regimentos internos dos Tribunais, os quais, à luz do art. 96, I, “a”, da CF têm tal natureza - federal, estadual, distrital, ou municipal - considerando vetusta lição de hermenêutica, consoante a qual não cabe ao intérprete diferençar onde o legislador não o faz, pelo menos não enquanto não se divisa razão suficiente para tanto, como no preceito em tela , com efeitos erga omnes e, ao menos em uma primeira análise, ex nunc, com a parada desde então da “execução da lei declarada inconstitucional”.

Celso Ribeiro Bastos ${ }^{3}$ noticia que a citada prerrogativa senatorial foi inserida no direito pátrio pela Carta de 1934, época em que o ordenamento jurídico brasileiro conhecia unicamente a arguição de inconstitucionalidade por via de defesa, com efeitos inter partes, de

\footnotetext{
${ }^{1}$ Cf. FERRAZ JR. Tercio Sampaio. Introdução ao Estudo do Direito. 6. ed. São Paulo: Atlas, 2008, pp. 26-7.

${ }^{2}$ Cf. SILVA, José Afonso da. Aplicabilidade das Normas Constitucionais. 8. ed. São Paulo: Malheiros, 2012, p. 180 , nota 15.

${ }^{3}$ Cf. BASTOS, Celso Ribeiro; MARTINS, Ives Gandra da Silva. Comentários à Constituição do Brasil. 4. vol. t. I. São Paulo: Saraiva, 1995, p. 178.
} 
forma que a finalidade da faculdade de suspensão da execução da lei declarada inconstitucional tinha a finalidade de obviar os inconvenientes do controle difuso no que concerne à eficácia de suas decisões - conformadoras de normas jurídicas dotadas do atributo da generalidade, entendido este na esteira das lições de Norberto Bobbio. ${ }^{4}$ Posteriormente, com a incorporação da ação direta à ordem jurídica brasileira, iniciaram-se fortes discussões a respeito da extensão de tal preceito às decisões declaratórias de inconstitucionalidade do Supremo em via principal. Entretanto, o Regimento Interno do Supremo Tribunal Federal em seu art. 178, positiva regra restringindo a comunicação ao Senado para fins do art. 52, X, da CF, aos casos de declaração de inconstitucionalidade na via difusa. Daí restando clara a função da resolução senatorial de outorga de efeitos erga omnes à decisão da Corte Maior.

Discute-se, na doutrina, quanto à obrigatoriedade - discricionariedade política ou vinculação - do Senado Federal declarar a suspensão da execução da lei nos casos de declaração de inconstitucionalidade, pelo STF, através da via de exceção. Quatro hipóteses as quais podem se sobrepor - exsurgem: (a) deveria, necessariamente, o Senado suspender, via resolução, a execução da lei declarada inconstitucional na mesma extensão em que o Supremo a considerou como tal (vinculação estrita); (b) poderia o Senado, simplesmente, não suspender a execução da lei declarada inconstitucional (discricionariedade política), (c) poderia ele suspender em parte lei declarada inconstitucional em sua totalidade pelo STF (ainda discricionariedade política), (d) poderia o Senado declarar toda a lei inconstitucional quando o STF a declara apenas em parte.

Antes de qualquer outra consideração, importa ressaltar a possibilidade da convivência de mais de uma interpretação adequada, ou seja, o Direito, consoante ressalta Fábio Ulhoa Coelho $^{5}$, pode ser objeto de dois níveis diversos do conhecimento, de tal arte que a depender do objetivo que o estudioso busca alcançar, o seu conhecimento pode ser científico - o qual demandará um juízo de veracidade, a excluir as proposições inconciliáveis - ou tecnológico o qual busca o(s) sentido(s) possível(is) das normas, não sendo viável a busca por uma verdadeira interpretação, de forma que estas não se excluem, como ocorre no conhecimento científico, mas convivem numa harmonia própria, afigurando-se como mais ou menos adequados à aplicação do Direito, o que, por sua vez, depende do esforço argumentativo apresentado pelo intérprete. Entendimento, ademais, na mesma esteira da lição de Kelsen da relativa indeterminação do ato de aplicação do Direito, do caráter de moldura do direito

\footnotetext{
${ }^{4}$ Cf. Teoria da Norma Jurídica. 5. ed. São Paulo: Edipro, 2012, p. 177 e ss.

${ }^{5}$ Cf. Curso de Direito Comercial. 16. ed. São Paulo: Saraiva, 2012, pp.45-46.
} 
aplicável em relação ao ato de produção jurídica, e da inexistência de uma única resposta correta, tendo em vista a inexistência de um critério de Direito Positivo que enseje a escolha, ao menos em definitivo e para todos os casos, por um determinado sentido dentro da múltipla significação do texto legal. ${ }^{6}$

Destarte, importa verificar qual a norma jurídica - produto da incidência da interpretação sobre os textos normativos, in casu, normativo-constitucionais, ou a significação extraída após a interpretação sistemática das diversas disposições constantes da ordem jurídica continente da norma ${ }^{7}$ - que exsurge como a mais consentânea com uma interpretação da Carta Republicana em sua inteireza, de modo a afigurar-se como a mais adequada para a aplicação da Constituição, ao lume do postulado - no sentido kantiano de condição de possibilidade do (adequado) conhecimento, no caso, da Lei Magna - da unidade da Constituição.

\subsection{Ilegitimidade e Usurpação de Competência}

A última das hipóteses retromencionadas deve ser descartada de plano, tendo em vista questões de absoluta incompetência e ilegitimidade, sob o prisma constitucional, do Senado Federal para controlar repressivamente, da forma ora analisada, a constitucionalidade de ato normativo - da parte não apreciada e não declarada como contrária à Constituição pelo STF -, usurpando competência constitucionalmente atribuída ao Supremo. Importante, entrementes, ressalvar que cabe ao Legislativo, em ordem jurídico-constitucional pátria, parcela da competência controladora repressiva da constitucionalidade, não no caso em questão, nem mesmo somente ao Senado Federal, posto que ao Congresso Nacional é atribuída a competência para sustar os atos normativos do Executivo que exorbitem do poder regulamentar - controle de constitucionalidade porque centrado em eventual gravame à legalidade (art. 50, II, CF) - ou dos limites de delegação legislativa - controle repressivo formal de constitucionalidade - consoante estatuído pelo art. 49, V, da Lei Maior.

\subsection{Obrigatoriedade ou Discricionariedade?}

\footnotetext{
${ }^{6}$ Cf. HANS, Kelsen. Teoria Pura do Direito. 7. ed, São Paulo: Martins Fontes, 2006, p. 388-94.

${ }^{7}$ Cf. ÁVILA, Humberto. Teoria dos Princípios. 13. ed. São Paulo: Malheiros, 2012, p. 33.
} 
Quanto à obrigatoriedade de o Senado suspender a execução do ato normativo inconstitucional, necessária a constatação de que a exegese do dispositivo supratranscrito pode levar à consideração de que ambas as conclusões são razoáveis, em uma primeira vista, e que somente uma interpretação sistemática da Carta Republicana pode levar a uma resposta constitucionalmente adequada, a qual se passa a realizar.

Manoel Gonçalves Ferreira Filho, afirma tratar-se de obrigação do Senado, pois, caso contrário, este teria o "poder de convalidar ato inconstitucional, mantendo-o, eficaz, o que repugna o nosso sistema jurídico ${ }^{8}$ ”. Contra a asserção do autor caberia aduzir a eficácia de norma jurídica individual inter partes da decisão em controle incidental, muito embora, em reforço à sua posição e ataque à tese contrária aqui apenas exposta, seja possível pugnar favoravelmente à hodierna e crescente corrente da objetivação do controle difuso de constitucionalidade, conforme outrora fora já defendido na Corte Suprema pelo Ministro Gilmar Ferreira Mendes.

Por sua vez, Celso Bastos entende caber ao Senado, unicamente, verificar a ocorrência dos pressupostos constitucionais autorizadores da declaração de inconstitucionalidade,

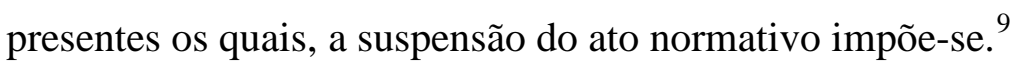

Por outro lado, Michel Temer aduz ser discrição do Senado a suspensão da execução da lei declarada inconstitucional pelo STF, podendo aquele a suspender, ou não de acordo com o seu entendimento, pois "o simples fato de o art. 52, X, possibilitar a suspensão total ou parcial da lei revela essa discricionariedade”. ${ }^{10}$ Tal afirmação, da maneira como posta pelo autor, carece de maior fundamentação, entretanto é possível entendê-la com supedâneo nos ensinamentos de José Afonso da Silva, para quem a maioria das regras de competência da Constituição - entre as quais a regra em exame, cujo caput do dispositivo em que se encontra inserta assim está redigido: “Compete privativamente ao Senado Federal” - seriam regras permissivas, isto é, conteriam simples faculdade ou autorização para o exercício do poder outorgado. ${ }^{11}$ Ademais, não é outra a lição de José Souto Maior Borges, o qual aduz que desde

\footnotetext{
${ }^{8}$ FILHO, Manoel Gonçalves Ferreira. Curso de Direito Constitucional. 34. ed. São Paulo: Saraiva, 2011, p. 43.

${ }^{9}$ Cf. BASTOS, Celso Ribeiro; MARTINS, Ives Gandra da Silva. Comentários à Constituição do Brasil. 4. vol. t. I. São Paulo: Saraiva, 1995, p. 179.

${ }^{10}$ Elementos de Direito Constitucional. 24. ed. São Paulo: Malheiros, 2012, pp. 48-49.

${ }^{11}$ Cf. SILVA, José Afonso da. Aplicabilidade das Normas Constitucionais. 8. ed. São Paulo: Malheiros, 2012, pp. 69-70.
} 
Forsthoff (Lehrbuch des Verwaltungsrechts, 3. ed., Beck, München, vol. 1º, p. 347) se sabe que toda atribuição de competência se expressa pelo modal deôntico da autorização. ${ }^{12}$

Afirma, igualmente, o autor, que as expressões “no todo” ou “em parte” são utilizadas em outros dispositivos constitucionais como o art. 66, $\S 1^{\circ}$, o qual possibilita ao Presidente vetar total ou parcialmente lei, ou seja, deixando à discrição deste a dimensão, extensão do veto. ${ }^{13}$ Chega a afirmar Temer que tais argumentos levam à conclusão de que poderia o Senado suspender em parte ato normativo declarado inconstitucional em sua integralidade pelo Supremo, o que não coaduna com a jurisprudência deste Tribunal, já que o próprio STF, malgrado entenda ser a suspensão da execução do ato normativo faculdade discricionária do Senado Federal, sob pena de mácula à separação de Poderes, entende também que a expressão “no todo ou em parte” significa ser impossível ao Senado ampliar ou reduzir o âmbito da declaração de inconstitucionalidade exarada por ele, o órgão do Poder constitucionalmente competente para tal controle.

Efetivamente, com o exposto, a outorga do referido poder ao Senado Federal, órgão político, que, conseguintemente, decide com base em critérios políticos, leva à conclusão de que se trata de poder facultativamente utilizável, e não poder-dever, deste órgão suspender a execução do ato normativo, máxime quando se considera que o constituinte originário poderia simplesmente outorgar, à decisão exarada pelo STF em sede de controle incidental, efeitos “erga omnes”, mesmo que “ex nunc”, mas não o fez, preferindo conferir um poder ao Senado federal, acrescentando pitadas a mais de controle político ao sistema de controle difuso de constitucionalidade - já enormemente político em sua feição de controle material (do conteúdo constante do descritor e do prescritor das normas jurídicas) - em nossa ordem jurídica, para decidir conforme seus critérios, que, como é cediço e demonstrado pela experiência do controle de constitucionalidade realizado por órgão político, são, como não poderiam deixar de ser, eminentemente políticos, envolvendo conveniência e oportunidade, critérios extrajurídicos, ou seja, não necessariamente correlatos aos critérios atinentes à conformidade com a Constituição.

Ademais, a abstrativização do controle difuso como já pretendeu o Ministro Gilmar Mendes lastreado na tese da mutação constitucional ocorrida com o art. 52, X, e na chamada transcendência da ratio decidendi, ao aproximar o controle pela via difusa do controle

${ }^{12}$ Cf. Prefácio à obra de Humberto Ávila, Sistema Constitucional Tributário. 5. ed. São Paulo: Saraiva, 2012, p. 53.

${ }^{13}$ Cf. TEMER. op. cit., pp. 48-49. 
concentrado $^{14}$, levaria à ineficácia daquele dispositivo constitucional, o que se afigura inconcebível face à constatação de que a Constituição não é composta de simples declarações sem valor ou sentido, mas de normas de eficácia jurídica plena, mesmo que mínima, conforme entendimento amplamente majoritário da doutrina constitucionalista brasileira - como se vê pelas obras de, v. g., Paulo Bonavides em seu Curso de Direito Constitucional, Ingo Sarlet em sua Eficácia dos Direitos Fundamentais, Luís Roberto Barroso em seu O Direito Constitucional e a Efetividade de Suas Normas, entre muitos outros -, desde a obra de José Afonso da Silva e aqui já citada: Aplicabilidade das Normas Constitucionais, quando se trata das comumente chamadas normas de princípio programático e de princípio institutivo ou organizativo, ou seja, daquelas classificadas como de eficácia limitada pelo referido mestre, malgrado não pareça, pelo menos no que concerne aos direitos fundamentais, ser uma classificação que se sustente hodiernamente, tendo em vista a construção jurídica de uma teoria dos princípios e de uma teoria dos direitos fundamentais que àquela pressupõe como seu alicerce, como demonstrado por Virgílio Afonso da Silva em recente obra. ${ }^{15}$ Vale dizer, não parece haver, atualmente, suporte normativo para tal tese no ordenamento jurídicoconstitucional brasileiro no referente aos dispositivos consagradores de direitos fundamentais, onde José Afonso da Silva vê em sua maioria normas de eficácia contida, restringível com base em reservas legais, parecendo não ser viável a subsistência de tal categoria de normas no que concerne aos direitos fundamentais, dada a restringibilidade conatural - com a prescindência das chamadas reservas legais - a esses direitos na sua qualidade de princípios, inobstante se reconheça a existência de regras veiculadoras de direitos fundamentais, $v$. $g$. os incisos XXXVI, XL, XLIV, LII, entre outros do art. $5^{\circ}$ da Carta Política.

Portanto, ante a maneira como o constituinte organizou o controle no sistema difuso, por mais que possa parecer mais correta a atribuição de efeitos aptos a espraiarem-se por todo ordenamento jurídico à decisão em controle por via de exceção, ou a automatização da suspensão da execução do ato normativo pelo Supremo por razões de estabilidade das relações, segurança jurídica, politicidade das decisões do STF, guardião máximo da Lei Magna, força normativa e supremacia desta, ainda parece mais correta, por todo o exposto, a exegese referente à atuação política e discricionária do Senado Federal.

\footnotetext{
${ }^{14}$ Cf. RE 197.917/SP, Rel. Min. Maurício Corrêa, 06.06 .2002 (Inf. 398/STF) e HC 82959/SP, Rel. Min. Marcos Aurélio. 23.02.2006 (Inf. 418/STF)

${ }^{15}$ Cf. SILVA, Virgílio Afonso da. Direitos Fundamentais: conteúdo essencial, restrições e eficácia. 2. ed. São Paulo: Malheiros, 2010.
} 
Quanto à possível melhor solução à hipótese, de lege ferenda, talvez nem mesmo a outorga de efeitos “erga omnes” à decisão em controle difuso, ou a automatização da suspensão da execução do ato normativo pelo Supremo conformem a solução mais consentâneo com a ordem constitucional brasileira, considerando que há casos em que o Supremo declara lei inconstitucional por diferença de um ou dois votos, o que demonstra que qualquer modificação de entendimento ou na composição dos membros do Tribunal pode levar a uma decisão oposta àquela proferida originariamente, o que leva à conclusão que tal matéria, ainda, precisa ser mais bem discutida e refletida dentro da ordem jurídica para que haja a segurança consentânea com uma decisão que valha para todos.

Afigura-se como uma solução possível, a outorga de efeitos “erga omnes” à decisão do Supremo em controle difuso no caso do entendimento dominante quanto à constitucionalidade ou inconstitucionalidade do ato normativo ser comungado por quorum elevado dos membros do Tribunal, um quorum suficiente para carrear segurança jurídica junto de si, entendida como pacificação de entendimento naquela Corte, de forma que simples mudanças corriqueiras na sua composição, no mínimo como regra, não acarretem mudança no posicionamento dominante dentre seus Ministros.

Já aquelas decisões que não atinjam o quorum requerido e razoável para que a decisão valha para todos, terão de ser mais debatidas e pensadas pelos juristas até que se chegue a um consenso razoável, o qual levará, em processos posteriores, ao quorum necessário para tal entendimento, agora difundido e aceito de forma mais ampla, valer para todos. Ou seja, o fato da decisão não obter consenso suficiente entre os Ministros já mostra a necessidade de reflexão sobre a matéria. Tais decisões terão efeitos entre as partes do processo, e até que, em momento posterior, e em outra lide, confirme-se o entendimento agora amplamente predominante pelo quorum necessário à outorga de efeitos “erga omnes”.

Quanto ao possível argumento de que tal problema relativo ao consenso se estenderia ao controle concentrado, apesar de não poder se negar completamente a ocorrência daquele, neste, cabe afirmar que o problema resta atenuado, tendo em vista que o próprio objeto da ação é a declaração de inconstitucionalidade do ato normativo com efeitos para todos, seus efeitos são “erga omnes” por natureza - a ação existe justamente para que o ato normativo contestado seja extirpado do sistema jurídico -, e não a resolução de questão diversa que depende da declaração de inconstitucionalidade, a qual é acessória; como as próprias designações demonstram, trata-se de ação direta, em oposição ao controle indireto que ocorre 
na via difusa. Igualmente, o problema da possível falta de consenso e consequente instabilidade do ordenamento sempre houve e sempre haverá em certa medida, afigurando-se até mesmo saudável em certos aspectos, já que permite a evolução e o desenvolvimento das ideias.

\subsection{Liberdade Quanto à Extensão da Suspensão?}

Quanto à possibilidade do Senado de suspender, em parte, lei declarada inconstitucional em sua totalidade pelo STF, parece mais razoável o entendimento segundo o qual se afigura impossível ao Senado ampliar ou reduzir o âmbito da declaração de inconstitucionalidade, pois estaria ele se imiscuindo no mérito da questão, na competência constitucional do Poder Judiciário de interpretar e aplicar o Direito posto.

Quer se dizer com isso que o Senado Federal, no que concerne à extensão da abrangência de sua resolução, está totalmente vinculado à decisão de mérito proveniente da cúpula do Judiciário, não podendo fugir das raias da decisão do Supremo Tribunal.

O argumento de Michel Temer, acima exposto, segundo o qual as expressões "no todo” ou “em parte” são utilizadas em outros dispositivos constitucionais como o art. 66, 1º o qual possibilita ao Presidente vetar total ou parcialmente lei, isto é, deixando à discrição deste a extensão do veto ${ }^{16}$, levando à ilação de que haveria a mesma discrição quanto à extensão da suspensão da executoriedade, não prevalece ante a constatação de que, ao contrário do que ocorre no primeiro caso, onde não há lei perfeita, mas sim mero projeto de lei dentro de seu processo de criação, e, portanto, nunca aplicado, nem aplicável a casos concretos, o segundo trata de lei já perfeita, válida - ao menos em um sentido fraco correspondente à mera existência no sistema jurídico - e potencialmente aplicável a casos concretos, dotada de eficácia jurídica e, ao menos pretensamente, social, o que acarretaria maior instabilidade no caso de possibilidade de suspensão apenas parcial lastreada em critérios políticos.

Entrementes, o motivo determinante para a distinção que se visa demonstrar entre as situações, repousa no fato de que, no segundo dos casos há controle de órgão competente para tal, hipótese em que, como sobredito, haveria ingerência indevida do Senado no mérito da questão, o qual cabe ao STF; já, na hipótese de veto do Presidente da República, não ocorreria qualquer ingerência do tipo, de forma que se trataria apenas de controle preventivo por parte

\footnotetext{
${ }^{16}$ Cf. TEMER, Michel. Elementos de Direito Constitucional. 24. ed. São Paulo: Malheiros, 2012, pp. 48-49.
} 
do chefe do Executivo, órgão competente para tal. Trata-se de situações distintas, as quais requerem tratamentos distintos.

\section{A EFICÁCIA PROSPECTIVA DA RESOLUÇÃO SENATORIAL}

Ao final, cabe ainda uma rápida tomada de posição quanto à polêmica final envolvendo o preceito constitucional objeto deste estudo, qual seja a atinente à eficácia da resolução senatorial no que diz respeito às relações jurídicas constituídas durante a vigência da norma tida por inconstitucional.

A doutrina controverte ao derredor da questão. ${ }^{17}$ Esta, por sua vez, se resume à díade possível de eficácias: ex tunc ou ex nunc.

Entrementes, não parece que o texto constitucional enseje outra interpretação senão a favorável à eficácia meramente prospectiva (ex nunc) da resolução senatorial. Isso é assim, porquanto, a Carta Magna fala em suspensão da executoriedade. Ora, suspensão é um termo cujo conteúdo semântico, em Direito, é perfeitamente delimitado, contrapondo-se à significação dada pela ciência jurídica ao termo interrupção, este denotador de efeitos retroativos; aquele de eficácia prospectiva. Ademais, é assente na doutrina que a manifestação do Senado não revoga nem anula a lei, unicamente lhe retirando a eficácia, já que a lei existiu, mesmo que nulamente; “se existiu, foi aplicada, revelou eficácia, produziu validamente seus efeitos”. ${ }^{18}$ Comentando a Carta Outorgada de 1969 (Emenda Constitucional no 1 , de 17 de Outubro de 1969), Pontes de Miranda afirmara que a lei constitucional continua eficaz "a despeito da decretação da nulidade, que é in casu, até que o Senado Federal suspenda a execução (= eficácia), no todo ou em parte, de tal regra jurídica”. ${ }^{19}$

\footnotetext{
${ }^{17}$ Pedro Lenza, referindo-se a levantamento procedido por Clèmerson Merlin Clève, aponta como favoráveis à posição que entende haver aí mera eficácia ex nunc Themístocles Cavalcanti, Oswaldo Aranha Bandeira de Mello, José Afonso da Silva, Nagib Slaibi Filho, Anna Cândida da Cunha Ferraz e Regina Macedo Nery Ferrari; de outra mão, aponta como filiados ao entendimento da eficácia ex tunc estão Clèmerson Merlin Clève, Gilmar Ferreira Mendes, Paulo Napoleão Nogueira Silva e Marcelo Caetano. Cf. Direito Constitucional Esquematizado. 15. ed. São Paulo: Saraiva, 2011, pp. 254-5.

${ }^{18}$ SILVA, José Afonso da. Aplicabilidade das Normas Constitucionais, 8. ed. São Paulo: Malheiros, 2012, p. 158; Pontes de Miranda. Comentários à Constituição de 1967 com a Emenda n. 1 de 1969, t. III/621, apud, SILVA, José Afonso da. Aplicabilidade das Normas Constitucionais, 8. ed. São Paulo: Malheiros, 2012, p. 158. ${ }^{19}$ Ibid., p. 158.
} 
Autores que pugnam pela eficácia ex tunc, normalmente baseiam-se no fato da lei inconstitucional ser algo inexistente, natimorto, nada. ${ }^{20}$ No entanto, cabe observar que "não passa de um preconceito equivocado pretender-se que melhor se prestigia a CF quando se nega qualquer validade e eficácia à norma dita ‘inconstitucional’”. ${ }^{21} \mathrm{Na}$ lição irretocável de Maior Borges:

\begin{abstract}
Tanto mais prestigiada estará a Carta Magna, e mais expansiva será a sua eficácia, quanto mais se considere que até a lei inconstitucional está nela prevista e regulada e lhe são constitucionalmente atribuídos efeitos, embora diversificados dos efeitos das normas conformes à CF, sobretudo no campo da revogação. Estas normas são expulsas do sistema segundo a regra: Lex posterior derogat priori (a norma posterior revoga a anterior). A lei inconstitucional depende porém de proclamação jurisprudencial e supressão de sua eficácia pelo Senado Federal (CF, art. 52, X). Quorum especial para a decretação de inconstitucionalidade (maioria absoluta dos tribunais), alterações jurisprudenciais (inconstitucional/constitucional), circunscrição do julgado às partes da demanda, no controle difuso de constitucionalidade, são exigências do sistema para proclamar-se a inconstitucionalidade das leis. Tanto aparato não seria necessário para dizer que o nada é coisa nenhuma - é a invectiva irônica de PONTES DE MIRANDA. Tudo evidencia que a lei inconstitucional existe. (BORGES, JOSÉ SOUTO MAIOR, 2012, p. 48-9)
\end{abstract}

Resta, destarte, evidente a regulamentação constitucional da lei antitética aos seus ditames e, pois, a sua existência jurídica. Logo, outra conclusão não se impõe senão aquela que confere eficácia prospectiva (ex nunc) às resoluções senatoriais previstas no art. 52, X, da Lei Maior.

\title{
3. CONSIDERAÇÕES FINAIS
}

Considerando a grande controvérsia ao derredor do tema, não se pretende, evidentemente, resolver a questão em um artigo científico - o que seria, ademais, deveras ingênuo -, nem estatuir uma solução definitiva - papel que não incumbe à doutrina, pois, como diria Reale, ela não se encontra em uma estrutura normativa de poder, muito embora sua contribuição à Ciência Jurídica e, conseguintemente, ao seu objeto, o Direito, seja fundamental para o aprimoramento deste último em seu papel de disciplinador das relações de intersubjetividade.

\footnotetext{
${ }^{20}$ Como, v.g., Alfredo Buzaid (Da Ação Direita de Declaração de Inconstitucionalidade no Direito Brasileiro) e Carmen Lúcia Antunes Rocha (Constituição e Constitucionalidade).

${ }^{21}$ Cf. BORGES, José Souto Maior. Prefácio à obra de Humberto Ávila, Sistema Constitucional Tributário. 5. ed. São Paulo: Saraiva, 2012, p. 48.
} 
Considerando, entrementes, toda argumentação expendida no corpo deste ensaio, não parece haver exegese para o art. 52, X, da Lei Maior, mais consentânea com o sistema constitucional pátrio, senão aquela que apresenta tal norma como conformadora de uma atuação política de um órgão político - o Senado Federal -, ao qual é outorgada discricionariedade para apreciar segundo juízos de oportunidade e conveniência (extrajurídicos) se é caso, ou não, de suspender-se a eficácia de lei tanto em seu sentido formal (espécies normativas enumeradas no art. 59 do Texto Constitucional), quanto em seu sentido material, sejam de que esfera da federação, mas desde que declaradas em controle difuso de constitucionalidade, pelo Supremo Tribunal Federal. Ademais, conforme aduzido por Temer:

(...) em face do princípio federativo, que, se a matéria questionada diz respeito a confronto entre lei municipal e a Constituição Estadual, ou entre lei estadual e a Constituição Estadual, pode e deve o Tribunal de Justiça, após declarar a inconstitucionalidade, remeter essa declaração à Assembleia Legislativa, para que suspenda a execução da lei (evidentemente, nos Estados em que as Constituições confiram essa competência à Assembleia). (TEMER, MICHEL, 2012, p. 48).

Trata-se de lição que importante, ante a necessária simetria que uma federação deve manter entre suas diferentes órbitas - como incompatíveis com a Constituição Federal.

Ademais, o equilíbrio entre os Poderes engendrado na Carta Constitucional de 1988 considerando não haver uma separação ideal do Poder, mas, no máximo, uma separação e um equilíbrio do Poder adequados para a ordem jurídica de determinado povo, de forma que cada ordenamento constrói o seu equilíbrio entre os seus órgãos do Poder -, com a conferência de atribuições, em certa medida, seguindo a ideia clássica de Montesquieu, segundo a qual uma experiência eterna atesta que todo homem que detém o poder tende a abusar do mesmo, indo o abuso até onde se lhe deparem limites, de molde que para não ser possível abusar desse poder, faz-se imperioso organizar a sociedade política de tal forma que o poder seja um freio ao poder, limitando o poder pelo próprio $\operatorname{poder}^{22}$, de forma a incumbir ao Poder Judiciário interpretar e aplicar a lei, não parece ser possível ao Legislativo, mais especificamente ao Senado Federal, alterar para mais ou para menos a extensão da declaração de inconstitucionalidade pelo Supremo Tribunal Federal.

\footnotetext{
${ }^{22}$ Cf. MONTESQUIEU. O Espírito das Leis. São Paulo: Martins Fontes, 2005, p. 166.
} 
Pelas mesmas razões, de outra mão, parece que o mecanismo do inciso X do artigo 52 da Constituição, não passa de mais um instrumento de controle do poder pelo poder, do Poder Judiciário pelo Poder Legislativo, conformando o sistema de freios e contrapesos (checks and balances) próprio do sistema de equilíbrio entre os Poderes construído pelo constituinte de 1988, com o que se reforça a tese, à guisa de fechamento, da conotação política e discricionária da competência senatorial estabelecida no multicitado, e objeto deste trabalho, art. 52, X da Carta Republicana.

\section{REFERÊNCIAS}

ÁVILA, Humberto. Sistema Constitucional Tributário. 5. ed. São Paulo: Saraiva, 2012.

ÁVILA, Humberto. Teoria dos Princípios. 13. ed. São Paulo: Malheiros, 2012.

BASTOS, Celso Ribeiro; MARTINS, Ives Gandra da Silva. Comentários à Constituição do Brasil. 4. vol. t. I. São Paulo: Saraiva, 1995.

BOBBIO, Norberto. Teoria da Norma Jurídica. 5. ed. São Paulo: Edipro, 2012.

COELHO, Fábio Ulhoa. Curso de Direito Comercial. 16. ed. São Paulo: Saraiva, 2012.

FERRAZ JR. Tercio Sampaio. Introdução ao Estudo do Direito. 6. ed. São Paulo: Atlas, 2008.

FILHO, Manoel Gonçalves Ferreira. Curso de Direito Constitucional. 34. ed. São Paulo: Saraiva, 2011.

HANS, Kelsen. Teoria Pura do Direito. 7. ed. São Paulo: Martins Fontes, 2006.

LENZA, Pedro. Direito Constitucional Esquematizado. 15. ed. São Paulo: Saraiva, 2011.

MONTESQUIEU. O Espírito das Leis. São Paulo: Martins Fontes, 2005.

SILVA, José Afonso da. Aplicabilidade das Normas Constitucionais. 8. ed. São Paulo: Malheiros, 2012. 
SILVA, Virgílio Afonso da. Direitos Fundamentais: conteúdo essencial, restrições e eficácia. 2. ed. São Paulo: Malheiros, 2010.

TEMER, Michel. Elementos de Direito Constitucional. 24. ed. São Paulo: Malheiros, 2012. 